\title{
Correction to: Dimensions of Peer Influences and Their Relationship to Adolescents' Aggression, Other Problem Behaviors and Prosocial Behavior
}

\author{
Albert D. Farrell $\mathbb{D}^{1}{ }^{1} \cdot$ Erin L. Thompson ${ }^{1} \cdot$ Krista R. Mehari $^{2}$
}

Published online: 30 November 2017

(C) Springer Science+Business Media, LLC, part of Springer Nature 2017

Correction to: J Youth Adolescence (2017) 46:1351-1369 https://doi.org/10.1007/s10964-016-0601-4

The original version of this article was inadvertently published with incorrect Supplementary Files without the copyright notice "*From Description of measures: Middle School Student Survey. By A. D. Farrell (2016). Richmond, VA: Virginia Commonwealth University. Copyright 2016 by Albert D. Farrell. Reprinted with permission" that was provided in the revised version.

The original article can be found online at https://doi.org/10.1007/ s10964-016-0601-4.

Albert D. Farrell

afarrell@vcu.edu

1 Department of Psychology, Virginia Commonwealth University, P.O. Box 842018, Richmond, VA 23284-2018, USA

2 Department of Psychology, Violence Prevention Initiative, The Children's Hospital of Philadelphia, 3535 Market St, Rm. 1464, Philadelphia, PA 19104, USA 